\title{
Annual screening with mammography and breast examination did not reduce breast cancer mortality in women 40-49 years of age
}

\author{
Miller AB, To T, Baines CJ, et al. The Canadian National Breast Screening Study-1: breast cancer mortality after 11 to 16 \\ years of follow-up. A randomized screening trial of mammography in women age 40 to 49 years. Ann Intern Med \\ 2002;137:305-12. \\ QUESTION: In women 40-49 years of age, does annual screening with mammography, \\ clinical breast examination (CBE), and breast self examination (BSE) instruction reduce \\ breast cancer mortality to a greater extent than a single CBE and BSE instruction?
}

\section{Design}

Randomised (allocation concealed*), blinded (outcome assessors), ${ }^{*}$ controlled trial with mean 13 years of follow up.

\section{Setting}

15 centres in Canada.

\section{Patients}

50489 women who were $40-49$ years of age and had no previous diagnosis of breast cancer, were not pregnant, and had not had mammography in the previous 12 months. 50430 (99.9\%) were included in the analysis.

\section{Intervention}

Sources of funding: 10 Canadian funding agencies.

All women received an initial CBE and instruction on BSE and were allocated to annual screening comprising mammography, CBE, and instruction and evaluation on BSE ( $\mathrm{n}=25$ 214) or to usual care $(\mathrm{n}=25216)$.

For correspondence: Dr A B Miller,

Deutsches

Krebsforschungszentrum,

Heidelberg, Germany. a.miller@dkfz-heidelberg.de

Abstract and commentary also appear in ACP Journal Club.

\section{Main outcome measure}

Breast cancer mortality.

\section{Main results}

Analysis was by intention to treat. During the first 5 years after study entry, the groups did not differ for breast cancer mortality rates and did not differ at each successive year of follow-up to $\geq 9$ years (table). 105 breast cancer deaths occurred in the mammography group and 108 in the usual care group. The study had $80 \%$ power to detect a $40 \%$ difference in breast cancer mortality between groups after 5 years.

\section{Conclusion}

In women 40-49 years of age, annual mammography and breast self examination did not reduce breast cancer mortality more than a single breast examination and usual health care.

*See glossary.

Annual breast cancer screening including mammography $v$ usual care to prevent breast cancer mortality $\dagger$

\begin{tabular}{llll} 
& \multicolumn{3}{c}{$\begin{array}{l}\text { Cumulative breast cancer } \\
\text { mortality rates/10 } 000 \text { women }\end{array}$} \\
\cline { 2 - 3 } $\begin{array}{l}\text { Years of } \\
\text { follow up }\end{array}$ & Mammography & Usual care & $\begin{array}{l}\text { Rate ratio } \\
(95 \% \text { Cl) }\end{array}$ \\
\hline $2-5$ & 2.26 & 2.12 & $1.07(0.75$ to 1.52$)$ \\
\hline 6 & 2.55 & 2.51 & $1.01(0.73$ to 1.41$)$ \\
\hline 7 & 3.04 & 2.90 & $1.05(0.78$ to 1.42$)$ \\
\hline 8 & 3.29 & 3.15 & $1.04(0.78$ to 1.40$)$ \\
\hline$\geq 9$ & 3.72 & 3.82 & $0.97(0.74$ to 1.27$)$ \\
\hline
\end{tabular}

†All comparisons are not significant.

\section{COMMENTARY}

At first glance, these 2 reports seem inconsistent: The study by Miller et al is an update of the Canadian National Breast Screening Study, continuing to show no hint of benefit in women 40-49 years of age; the review by Humphrey $e$ al is a USPSTF meta-analysis extending a recommendation for mammography to this age group for the first time. Ironically, the Canadian study was judged to be the highest quality study of all those evaluated by the USPSTF. Even with $>50000$ participants, the Canadian study did not have the power to detect a protective effect $<40 \%$; the USPSTF meta-analysis found a much smaller benefit of $15 \%$ in the $40-49$ year age group. The $95 \%$ confidence intervals/credible intervals of the reduction in breast cancer mortality in the 2 studies $(0.74$ to $1.27 v 0.73$ to 0.99$)$ overlap widely. The absolute reduction in breast cancer mortality is low in all age groups. For women $40-49$ years of age, it is estimated to be $<1 / 10000$ per year. For older women, the benefit is slightly greater and the confidence intervals more clearly exclude the null result.

At what price is this modest benefit obtained? Surprisingly, in the appendix the USPSTF states: "A systematic review of adverse effects was beyond the scope of our review". The evidence for adverse effects includes false positive results, believed to occur in $6.5 \%$ of mammograms; ${ }^{1}$ radiogenic breast cancer, estimated by the USPSTF to negate $<10 \%$ of the breast mortality benefit; and diagnosis and treatment of cancer that may not become clinically important. In the Canadian study, about 14\% more diagnoses of in situ or invasive breast cancer occurred in the screened group than in the usual care group; this difference persisted to almost 10 years after the intervention ended. In 2 Swedish trials including older women, 35\% more women received major surgery (mastectomy or lumpectomy) and 25\% more women received radiation in the screened groups. ${ }^{2}$ These results suggest that this may be a more substantial problem than previously thought.

How can we convey these results to our patients? For women $40-49$ years of age, the estimated benefit of mammography is small $(15 \%$, or $<1 / 10000$ breast cancer deaths prevented per year) and the evidence of benefit is weak, with confidence intervals nearly overlapping 1 . The risk of false positive results is higher at this age, as is the potential for radiation carcinogenesis. ${ }^{3}$ The absolute benefit might be greater in women at high risk because of a positive family Continued on next page 


\title{
Review: mammography reduces breast cancer mortality rates
}

\author{
Humphrey LL, Helfand M, Chan BK, et al. Breast cancer screening: a summary of the evidence for the U.S. Preventive \\ Services Task Force. Ann Intern Med 2002;137:347-60.

\section{QUESTION: How effective is breast cancer screening with mammography, clinical breast examination (CBE), and breast self examination (BSE) in preventing breast cancer mortality?}

\section{Data sources}

Studies were identified by searching Medline (19942001), Premedline (December 2001 to February 2002), and the Cochrane Controlled Trials Register; reviewing the reference lists of previous reviews, commentaries, and meta-analyses; and contacting experts in the field.

\section{Study selection}

Studies were selected if they were randomised controlled trials (RCTs) of breast cancer screening and had a relevant clinical outcome (advanced breast cancer, breast cancer mortality, or all cause mortality).

\section{Data extraction}

Data were extracted on patient population, study design, potential flaws, missing information, analysis, and length of follow up. US Preventive Services Task Force (USPSTF) criteria were used to assess study quality (good, fair, or poor). The primary endpoint was breast cancer mortality.

\section{Main results}

8 RCTs (479 987 women) (154 publications) met the selection criteria: 4 evaluated mammography, and 4 evaluated mammography plus CBE. 7 trials were rated fair quality, and 1 was rated poor quality. The mean follow up was 14 years. Meta-analysis of the 7 fair trials showed that mammography screening led to a modest reduction in breast cancer mortality across all age groups, with greater benefit conferred in older women (table). The results were consistent with those of 5 of 7 previous meta-analyses identified in the search for trials.
Mortality reductions in trials of mammography plus CBE were similar to those of trials of mammography alone. 2 RCTs of BSE met the selection criteria. Both trials showed no difference in breast cancer mortality rates in women instructed in BSE and in non-instructed women.

\section{Conclusions}

Fair quality evidence from randomised controlled trials shows that mammography screening is effective in reducing breast cancer mortality. Biennial and annual screening are equally effective. Clinical breast examination confers no additional benefit. Instruction in breast self examination, as a single screening method, is ineffective.
Source of funding: Agency for Healthcare Research and Quality.

For correspondence: Dr L L Humphrey, Oregon Health $\mathcal{E}^{2}$ Science University, Portland, OR, USA. Humphrey.Linda@ portland.va.gov

Abstract and commentary also appear in ACP Journal Club.

Screening with mammography $v$ usual care to prevent breast cancer mortality at mean 14 years follow up*

\begin{tabular}{|c|c|c|c|}
\hline Age groups & $\begin{array}{l}\text { Number of } \\
\text { trialst }\end{array}$ & RRR $(95 \%$ Crl) & NNS (Crl) \\
\hline All ages (39-74 y) & 7 & $16 \%$ (9 to 23 ) & 1224 (665 to 2564 ) \\
\hline$<50$ years & 7 & $15 \%(1$ to 27$)$ & $1792(674$ to 10540$)$ \\
\hline$\geq 50$ years & 7 & $22 \%$ (13 to 30 ) & 838 (494 to 1676 ) \\
\hline
\end{tabular}

Continued from previous page

history. However, mammography has been shown to be less sensitive in this group, ${ }^{4}$ and if the family history results from inherited radiation sensitivity, ${ }^{5}$ the risk of radiogenic breast cancer will be further increased.

For women $\geq 50$ years, the evidence of a $20-25 \%$ relative benefit in breast cancer mortality is stronger and exceeds $1 / 10000$ per year. An important issue in this group is the discovery of cancer that might not have caused symptoms, especially in women with comorbid conditions and a limited life span.

Unfortunately, it is clear that most breast cancer deaths will not be prevented by mammography at any age. Perhaps the enormous resources devoted to the debate, promotion, and provision of mammography could be better used to study the efficacy of more sensitive detection systems ${ }^{6}$ or to develop predictive models with greater discriminatory power. ${ }^{7}$

Laura Rees Willett, MD Robert Wood Johnson Medical School New Brunswick, New Jersey, USA

1 Christiansen CL, Wang F, Barton MB, et al. Predicting the cumulative risk of false-positive mammograms. J Natl Cancer Inst 2000;92:1657-66.

Gotzche PC, Olsen O. Is screening for breast cancer with mammography justifiable? Lancet 2000;355:129-34.

Feig SA, Ehrlich SM. Estimation of radiation risk from screening mammography: recent trends and comparison with expected benefits. Radiology 1990;174;638-47. Kerlikowske K, Grady D, Barclay J, et al. Effect of age, breast density, and family history on the sensitivity of first screening mammography. JAMA 1996;276:33-8.

$\mathrm{Su}$ Y, Swift M. Mortality rates among carriers of ataxia-telangiectasia mutant alleles. Ann Intern Med 2000;133:770-8.

Stoutjesdijk MJ, Boetes C, Jager GJ, et al. Magnetic resonance imaging and mammography in women with a hereditary risk of breast cancer. J Natl Cancer Inst 2001:93:1095-102.

Rockhill B, Spiegelman D, Byrne C, et al. Validation of the Gail et al. model of breast cancer risk prediction and implications for chemoprevention. J Natl Cancer Inst 2001;93:358-66. 